\title{
Mercedes Benz craniosynostosis
}

\author{
Dhaval Shukla \\ Department of Neurosurgery, National Institute of Mental Health and Neurosciences, Bengaluru, Karnataka, India
}

A 2-year-old girl presented with an abnormal shaped head since early infancy. Her growth and development were normal. A computerized tomography (CT) scan showed a fusion of sagittal and bilateral lambdoid sutures, typical of Mercedes Benz pattern craniosynostosis [Figure 1]. Except for widened subarachnoid spaces in the frontal region, she did not have any brain anomalies.

Mercedes Benz pattern craniosynostosis is also known as bilateral lambdoid and sagittal synostosis (BLSS). It was first described in 1976 by Neuhauser in a series of seven patients with synostosis of the sagittal and lambdoid sutures, short stature, and developmental delay. ${ }^{[1]}$ The term "Mercedes Benz" syndrome was coined by Moore in 1998 due to the characteristic appearance of the fused sutures on three dimensional CT imaging. ${ }^{[1]}$
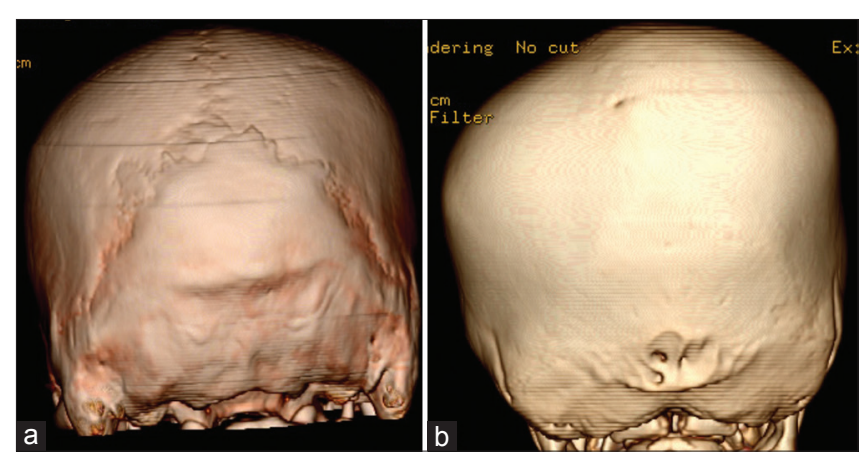

Figure 1: (a) Computerized tomography scan with surface shaded display of a child with normal brain imaging showing normal sagittal and both lambdoid sutures, (b) Computerized tomography scan of patient showing fusion of sagittal and both lambdoid sutures typical of Mercedes Benz pattern

\section{Address for correspondence:}

Dr. Dhaval Shukla, Department of Neurosurgery, National Institute of Mental Health and Neurosciences, Bengaluru - 560 029, Karnataka, India. E-mail: neurodhaval@rediffmail.com

\begin{tabular}{|l|l|}
\hline \multicolumn{2}{|c|}{ Access this article online } \\
\hline Quick Response Code: & Website: \\
\hline & www.ruralneuropractice.com \\
\cline { 2 - 3 } & \\
\hline
\end{tabular}

BLSS is a rare disorder characterized by invagination of the occipital squama resulting in a step-like deformity of the occiput, and a typical head shape described as anterior turricephaly with mild brachycephaly. ${ }^{[2]}$ Locally marked growth restriction is evident in the posterior fossa with the compensatory secondary expansion of the anterior fossa manifesting a degree of frontal bossing which mimics bicoronal synostosis. ${ }^{[3]}$ The incidence of BLSS is $1.4 \%{ }^{[4]}$ BLSS is a heterogeneous disorder with syndromic, chromosomal, and isolated forms. ${ }^{[1]}$ The associated anomalies include the Chiari I malformation (CM), hydrocephalus, and venous anomalies. ${ }^{[2]}$ Although, the appearance of frontal bossing could lead to inadvertent surgery in the frontal region, attention to the occipital region with wide early suture excision and vault shaping is indicated. ${ }^{[3]}$ Children, in addition, require foramen magnum decompression if $\mathrm{CM}$ is present. ${ }^{[2]}$

\section{Financial support and sponsorship} Nil.

\section{Conflicts of interest}

There are no conflicts of interest.

\section{References}

1. Hing AV, Click ES, Holder U, Seto ML, Vessey K, Gruss J, et al. Bilateral lambdoid and sagittal synostosis (BLSS): A unique craniosynostosis syndrome or predictable craniofacial phenotype? Am J Med Genet A 2009;149A: 1024-32.

2. Pillai S, Cochrane D, Singhal A, Steinbok P. Bilateral lambdoid and posterior sagittal craniosynostosis - Management, evolution, and outcome. Childs Nerv Syst 2013;29:2117-21.

3. Moore MH, Abbott AH, Netherway DJ, Menard R, Hanieh A. Bilambdoid and posterior sagittal synostosis: The Mercedes Benz syndrome. J Craniofac Surg 1998;9:417-22.

4. Rhodes JL, Kolar JC, Fearon JA. Mercedes Benz pattern craniosynostosis. Plast Reconstr Surg 2010;125:299-304.

This is an open access article distributed under the terms of the Creative Commons Attribution-NonCommercial-ShareAlike 3.0 License, which allows others to remix, tweak, and build upon the work non-commercially, as long as the author is credited and the new creations are licensed under the identical terms.

For reprints contact: reprints@medknow.com

How to cite this article: Shukla D. Mercedes Benz craniosynostosis. J Neurosci Rural Pract 2016;7:176. 